\title{
Temperature stability of the Transformer Position Transducer for Pneumatic Cylinder
}

\author{
Mehran Mirzaei, Pavel Ripka, Andrey Chirtsov, and Vaclav Grim \\ Faculty of Electrical Engineering, Czech Technical University, Prague 16627, Czech Republic \\ (e-mails: mirzameh@fel.cvut.cz, ripka@fel.cvut.cz)
}

\begin{abstract}
This paper presents the analysis and design of a transformer position sensor for pne umatic cylinder considering tempe rature stability. Two solenoid coils as excitation coil and pick up coil around cylinder are used for position transducer. The effects of temperature of aluminum cylinder and iron rod with diffe rent ferromagnetic materials on position sensor performance are analyzed and measured. We found that the effect of temperature de pendence of shell resistivity is dominant, while the effect of permeability change is negligible. Based on the simulations and measurement we suggest simple method of tempe rature compensation.
\end{abstract}

Index Terms-Transformer position transducer, pneumatic cylinder, temperature stability, ferromagnetic iron rods.

\section{INTRODUCTION}

Position sensors are key components for the industrial automation [1]-[3]. Detection of piston position inside aluminum shell of pneumatic cylinder is not easy task. Different methods were introduced, such as direct mounting of sensors inside the pis ton rod, microwave sensors mounted on the piston, optical or magnetic scales, which are not reliable and are mechanically complicated. The most popular method used in the industry is using external sensors, which measure magnetic field of permanent magnet mounted on the piston. It needs large number of sensors with complicated signal processing and expensive non ferromagnetic iron rod. A simpler method is to measure inductance of solenoid coil around cylinder [4]-[6]. The problem of this solution is slow response and large temperature dependence [5]-[6]. Therefore, we designed novel position sensor based on transformer configuration [7].

In this paper, temperature stability of a transformer-based position sensor for a pneumatic cylinder with an aluminum shell, an aluminumpis ton and different ferromagnetic iron rods is analyzed and measured. A simplified and fast 2D axisymmetric analytical method and 2D time harmonic axisymmetric finite element method (FEM) are utilized for simulations and analysis. Four iron rods with different magnetic characteristics are considered.

\section{MODEL}

The model and dimensions and parameters of a pneumatic cylinder with transformer position sensor are presented in Table I and Fig. 1. The iron rod and aluminum piston and cylinder are parts of the pneumatic cylinder. Two layers of windings with axis ymmetric configuration are used for transformer position transducer: the first layer is excitation coil and second layer is pick up coil. The electrical conductivity temperature dependency are measured and presented in Table II for aluminum cylinder and iron rods using (1).

$\sigma\left(\theta^{\circ} \mathrm{C}\right)=\sigma\left(20^{\circ} \mathrm{C}\right) /(1+c \cdot(\theta-20))$

Table I

Transformer position transducer parameters

\begin{tabular}{|l|l|}
\hline \multicolumn{1}{|c|}{ Parameter } & \multicolumn{1}{|c|}{ Value } \\
\hline Cylinder outer diameter, $D_{\mathrm{co}}$ & \\
Cylinder inner diameter, $D_{\mathrm{ci}}$ & $60(\mathrm{~mm})$ \\
Cylinder axial length, $L_{\mathrm{c}}$ & $56(\mathrm{~mm})$ \\
Piston outer diameter, $D_{\mathrm{po}}$ & $500(\mathrm{~mm})$ \\
Piston inner diameter, $D_{\mathrm{pi}}$ & $56(\mathrm{~mm})$ \\
Piston axial length, $L_{\mathrm{p}}$ & $20(\mathrm{~mm})$ \\
Iron rod diameter, $D_{\mathrm{i}}$ & $10(\mathrm{~mm})$ \\
Iron rod axial length, $L_{\mathrm{i}}$ & $20(\mathrm{~mm})$ \\
Number of turns for the excitation coil, $N_{\mathrm{e}}$ & $700(\mathrm{~mm})$ \\
Number of turns for pick up coil, $N_{\mathrm{pc}}$ & 800 \\
Wire diameter, $D_{\mathrm{w}}$ & 693 \\
\hline
\end{tabular}

\section{SIMPLIFIED MODEL}

A simple model without finite length effects of pneumatic cylinder is developed for fast evaluations of iron rod and aluminum cylinder materials and excitation current frequency. The general governing differential equation [8] is in (2) for 5 regions of computational model (Fig. 2). Region 1 is for iron rod (zero to radius $r_{1}$ ), region 2 is air region (radius $r_{1}$ to $r_{2}$ ), region 3 is aluminum cylinder (radius $r_{2}$ to $r_{3}$ ), region 4 is excitation coil (radius $r_{3}$ to $r_{4}$ ) and region 5 is pick up coil and air region beyond pick up coil (radius $r_{4}$ to infinite).

$\frac{\partial^{2} A_{\varphi, n}}{\partial r^{2}}+\frac{1}{r} \frac{\partial A_{\varphi, n}}{\partial r}-\frac{A_{\varphi, n}}{r^{2}}-\sigma u j \omega A_{\varphi, n}=-\mu J_{s}, \quad(\omega=2 \pi f)$ 


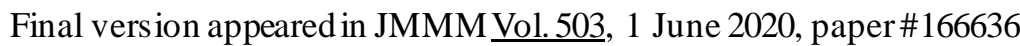

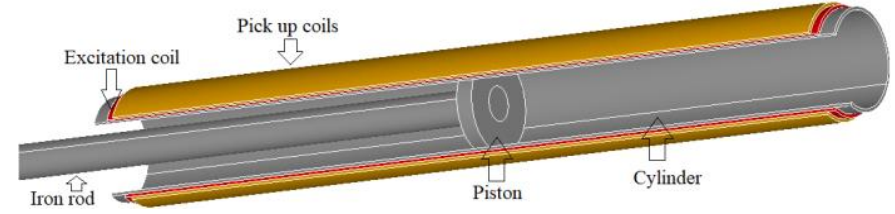

Fig. 1. Pneumatic cylinder with transformer position sensor

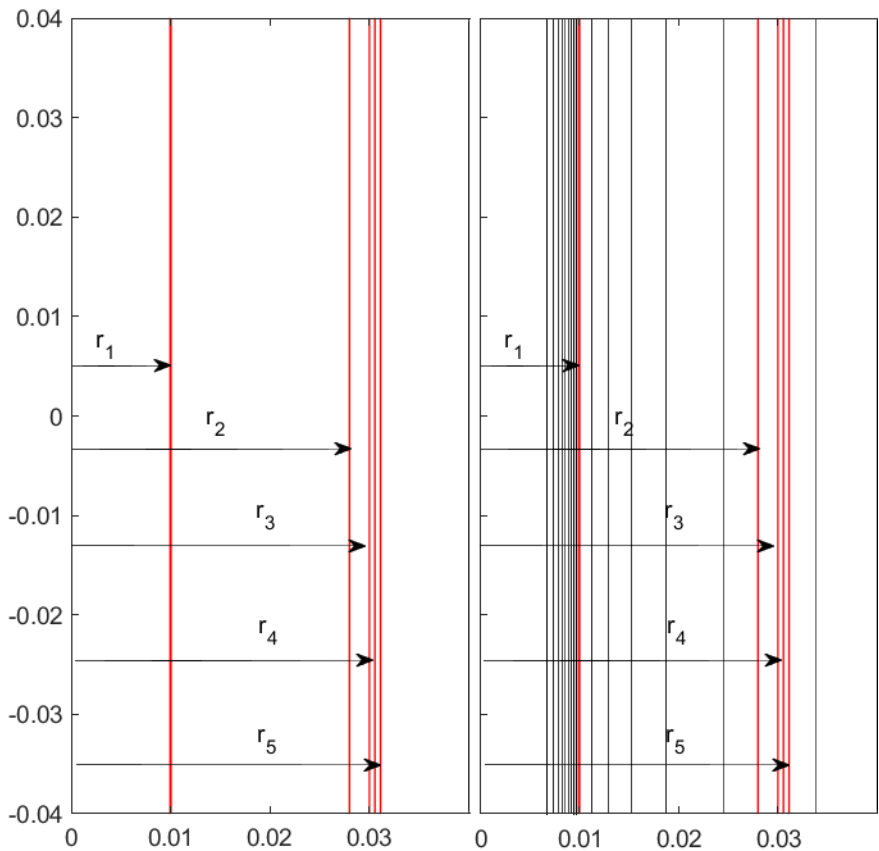

Fig. 2. Analytical model for pneumatic cylinder (left) and magnetic flux distribution in partial model of pneumatic cylinder

Table II

Temperature dependency coefficients- conductivity

\begin{tabular}{|l|c|c|}
\hline Materials & $\left.\boldsymbol{\sigma ( 2 0}{ }^{\circ} \mathbf{C}\right)-\mathbf{M S} / \mathbf{m}$ & $\boldsymbol{c}$ \\
\hline Al cylinder & 30.5 & 0.0041 \\
\hline Iron rod 1 & 6.31 & 0.0069 \\
\hline Iron rod 2 & 4.11 & 0.0051 \\
\hline Iron rod 3 & 4.59 & 0.0049 \\
\hline Iron rod 4 & 5.69 & 0.0051 \\
\hline
\end{tabular}

where, $A_{\varphi, \mathrm{n}}$ is azimuthal magnetic vector potential in region $\mathrm{n}$, $\sigma$ is conductivity, $\mu$ is magnetic permeability, $J_{\mathrm{s}}$ is current density in the excitation coil region and $f$ is frequency. The solutions of (2) for 5 regions are as follows:

$A_{\varphi, 1}=C_{11} \cdot \operatorname{Besseli}\left(1, \lambda_{i} \cdot r\right), \lambda_{i}=\sqrt{j \omega \sigma \mu_{i, r} \mu_{0}}$

$A_{\varphi, 2}=C_{21} \cdot r+C_{22} \cdot \frac{1}{r}$

$A_{\varphi, 3}=C_{31} \cdot \operatorname{Besseli}\left(1, \lambda_{a} \cdot r\right)+C_{32} \cdot \operatorname{Besselk}\left(1, \lambda_{a} \cdot r\right)$,

$\lambda_{a}=\sqrt{j \omega \sigma \mu_{0}}$

$A_{\varphi, 4}=C_{41} \cdot r+C_{42} \cdot \frac{1}{r}-\frac{\mu_{0} J_{s} r^{2}}{3}$

$A_{\varphi, 4}=C_{52} \cdot \frac{1}{r}$

$C_{11}, C_{21}, C_{22}, C_{31}, C_{32}, C_{41}, C_{52}$ are constants which can be calculated using boundary conditions between regions 1 to 5
[8]. $\mu_{0}$ and $\mu_{\mathrm{i}, \mathrm{r}}$ are air permeability and iron rod relative permeability, respectively.

The self inductance of excitation coil with current amplitude $I_{\mathrm{m}}, L_{\mathrm{s}}$, induced voltage in the pick up coil, $U_{\mathrm{M}}$ and mutual inductance, $M$ are calculated in (4) [8]. The variations of mutual inductance versus iron rod conductivity and relative permeability are shown in Fig. 3, which shows mutual inductance and induced voltage is less sensitive to iron rod conductivity and relative permeability at higher frequencies because of big reaction fields of induced eddy currents in the aluminum cylinder [7].

$$
\begin{aligned}
& L_{e}=\frac{N_{e} 2 \pi}{\left(r_{4}-r_{3}\right) I_{m}}\left(\begin{array}{l}
C_{41} \cdot \frac{\left(r_{4}^{3}-r_{4}^{3}\right)}{3}+C_{42} \cdot\left(r_{4}-r_{3}\right)- \\
\frac{\mu_{0} J_{s}}{12} \cdot\left(r_{4}^{4}-r_{4}^{4}\right)
\end{array}\right) \\
& U_{M}=-j \omega M \cdot I_{m}, M=\frac{N_{p c} 2 \pi}{\left(r_{4}-r_{3}\right) I_{m}} C_{52} \cdot\left(r_{5}-r_{4}\right)
\end{aligned}
$$

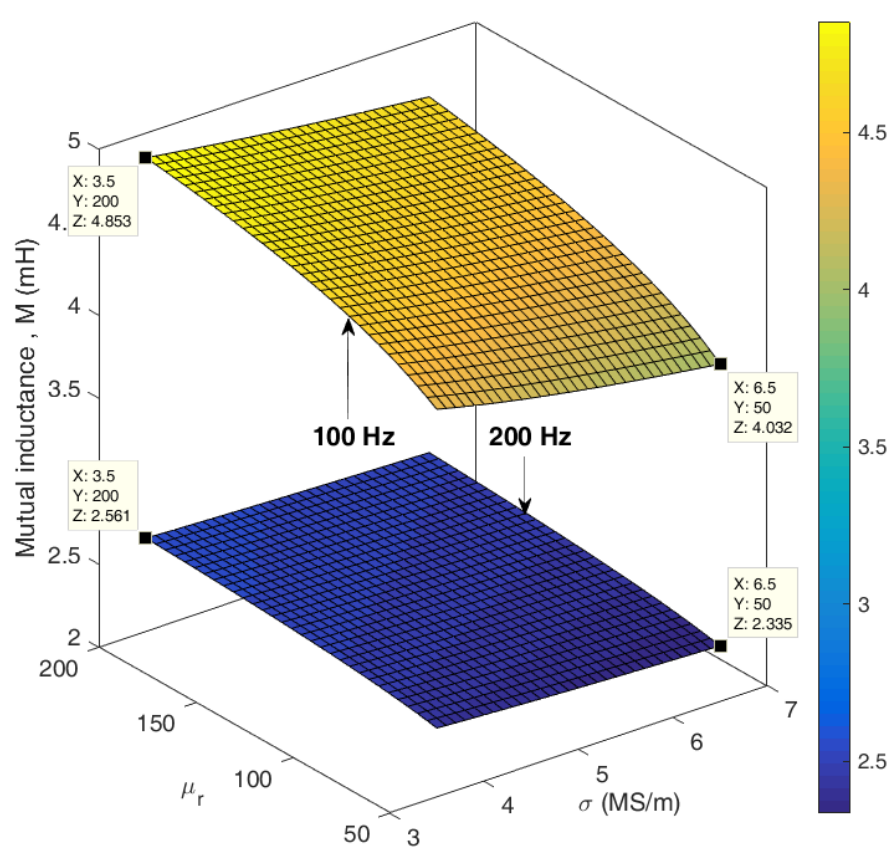

Fig. 3. Variation of mutual inductance between excitation coil and pick up coil versus iron rod conductivity and iron rod permeability at $100 \mathrm{~Hz}$ and $200 \mathrm{~Hz}$

\section{IRON ROD RELATIVE PERMEABILITY ESTIMATION}

Fig. 4 shows setup for measurement to estimate relative magnetic permeability and evaluate temperature effect as presented in Table III. The relative magnetic permeability values are estimated for the best fit between induced voltage in the pick up coil calculated by FEM and measured.

Table III

Temperature dependency coefficients- permeability

\begin{tabular}{|c|c|c|}
\hline Materials & $\boldsymbol{\mu}_{\mathbf{r}}\left(\mathbf{2 5}^{\mathbf{}} \mathbf{C} \mathbf{C}\right.$ & $\boldsymbol{\mu}_{\mathbf{r}}\left(\mathbf{5 0}^{\circ} \mathbf{C}\right)$ \\
\hline Iron rod 1 & $119.42(100 \%)$ & $124.35(104.1 \%)$ \\
\hline Iron rod 2 & $83.41(100 \%)$ & $87.04(104.4 \%)$ \\
\hline Iron rod 3 & $90.66(100 \%)$ & $95.38(105.2 \%)$ \\
\hline Iron rod 4 & $114.83(100 \%)$ & $116.64(101.6 \%)$ \\
\hline
\end{tabular}




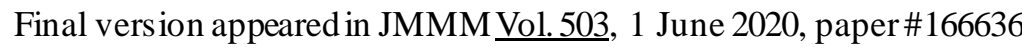

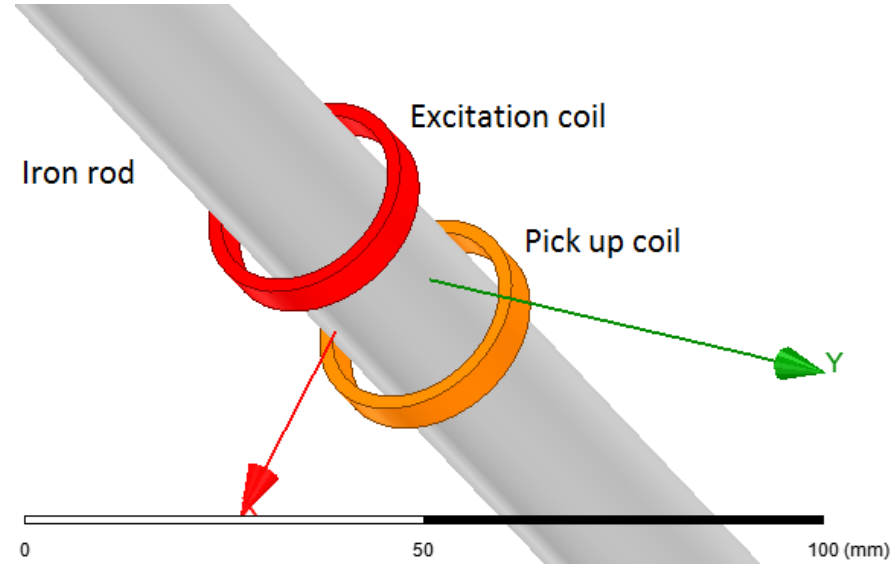

Fig. 4. Proposed model for relative permeability measurement

The magnetic permeability increases with increasing temperature, which was expected for solid irons and ferromagnetic materials [9]-[10].

\section{EXPERIMENTAL RESULTS}

The experimental set-up for a pneumatic position sensor and reference potentiometric position sensor with $500 \mathrm{~mm}$ range is shown in Fig. 5. Induced voltage is measured using a Lock-in amplifier.

\section{A. At Room Temperature}

Meas ured induced voltages in the pick up coil at $100 \mathrm{~Hz}$ and $200 \mathrm{~Hz}$ are shown in Fig. 6. Excitation coil is connected to a signal generator with $50 \Omega$ internal resistance with voltage amplitude $2.5 \mathrm{~V}$. Excellent linearity of $0.65 \%$ is noticed especially at $200 \mathrm{~Hz}$ between $50 \mathrm{~mm}$ and $450 \mathrm{~mm}$ of piston positions for real part (Re) and imaginary part (Im) of the induced voltage, which shows suitability of proposed position sens or for pneumatic cylinder, as the piston stroke is shorter than the cylinder leng th for real pneumatic cylinders [7]. Effects of different iron rods with different conductivities and relative permeabilities are slightly dis tinguishable in the imaginary part of the induced voltage at $100 \mathrm{~Hz}$. Fig. 7 shows bigger magnetic field strengths using FEM at starting point of piston position in the pneumatic cylinder, which causes higher imaginary part of induced voltages at starting point in comparis on with end position of piston.

\section{B. At $50{ }^{\circ} \mathrm{C}$}

Iron rods temperature effects on the induced voltages are presented in Table IV, which shows small effects on the induced voltage especially in imaginary part of voltage. Only iron rods were heated for higher temperature, $50{ }^{\circ} \mathrm{C}$. The corresponding maximum position temperature error was $0.4 \mathrm{~mm} / \mathrm{K}$ for real part and $0.1 \mathrm{~mm} / \mathrm{K}$ for imaginary part.

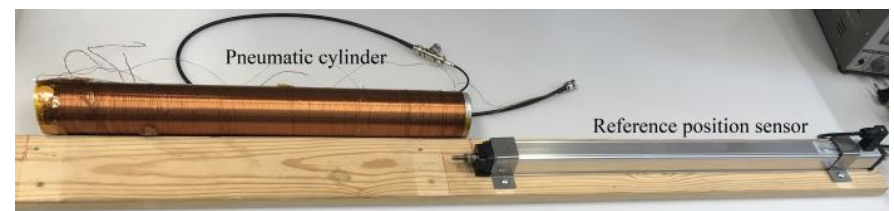

Fig. 5. Pneumatic cylinder and reference position sensor
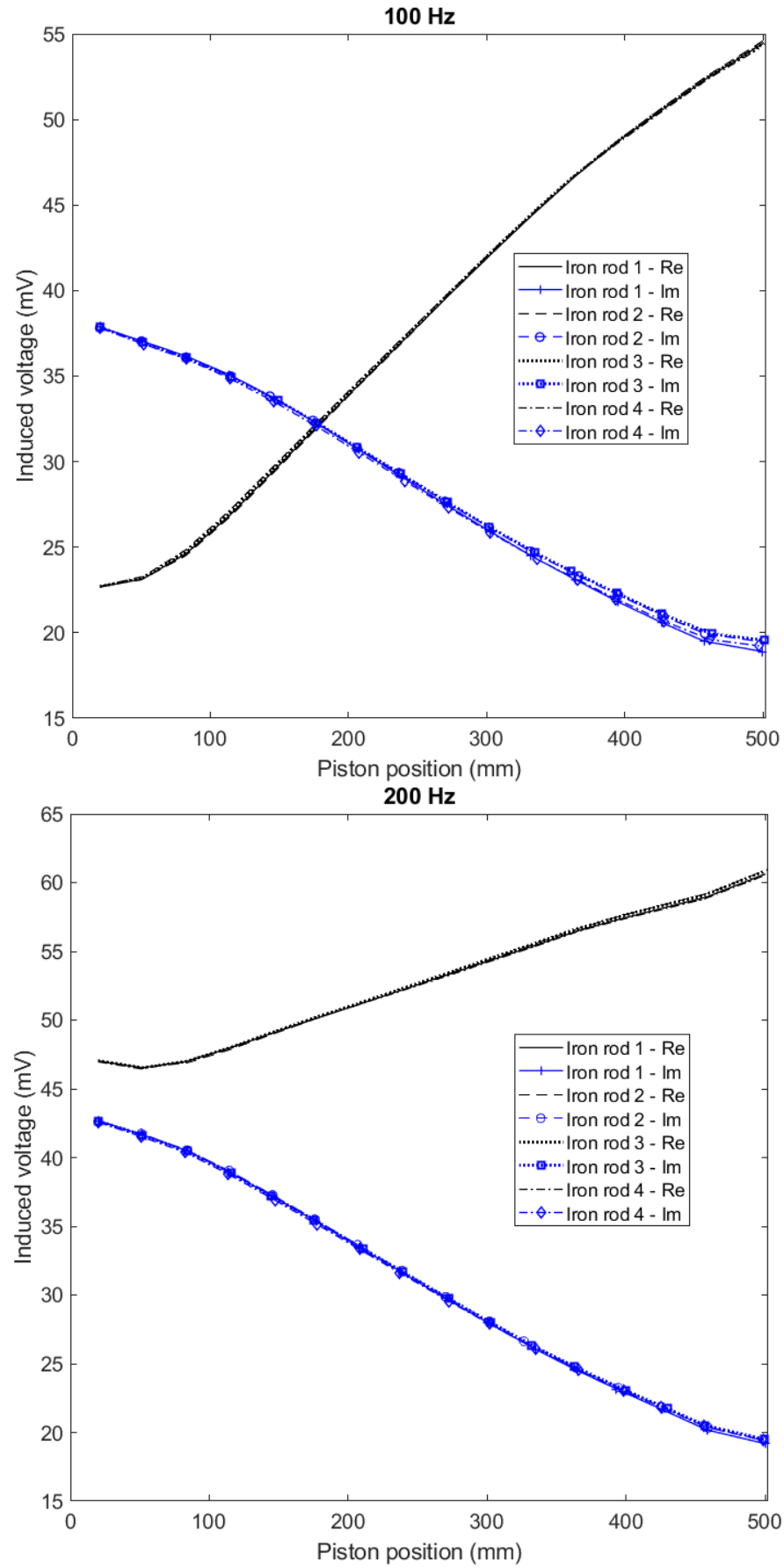

Fig. 6. Measured induced voltage in pick up coil versus iron rod and piston position-

Table IV

Induced voltages $(\mathrm{mV})$ comparison for different iron rods at $100 \mathrm{~Hz}-$ Measurement

\begin{tabular}{|c|c|c|c|c|c|}
\hline \multicolumn{2}{|c|}{ Piston position } & $\begin{array}{c}\text { Iron } \\
\text { Rod 1 }\end{array}$ & $\begin{array}{c}\text { Iron } \\
\text { Rod } 2\end{array}$ & $\begin{array}{c}\text { Iron } \\
\text { Rod } 3\end{array}$ & $\begin{array}{c}\text { Iron } \\
\text { Rod } 4\end{array}$ \\
\hline \multirow{2}{*}{$250 \mathrm{~mm}$} & $\operatorname{Re}$ & $\begin{array}{l}37.93 / \\
38.35\end{array}$ & $\begin{array}{c}37.9 / \\
38.6\end{array}$ & $\begin{array}{l}38.05 / \\
38.55\end{array}$ & $\begin{array}{c}38.1 / \\
-\end{array}$ \\
\hline & $\mathrm{Im}$ & $\begin{array}{l}28.53 / \\
28.48\end{array}$ & $\begin{array}{c}28.65 / \\
28.8\end{array}$ & $\begin{array}{l}28.68 / \\
28.68\end{array}$ & $\begin{array}{l}28.41 / \\
28.52\end{array}$ \\
\hline \multirow{2}{*}{$450 \mathrm{~mm}$} & $\operatorname{Re}$ & $\begin{array}{l}51.9 / \\
52.7 \\
\end{array}$ & $\begin{array}{l}52.0 / \\
52.97 \\
\end{array}$ & $\begin{array}{c}51.92 / \\
53.1\end{array}$ & $\begin{array}{l}51.8 / \\
52.42 \\
\end{array}$ \\
\hline & Im & $\begin{array}{l}19.76 / \\
19.61\end{array}$ & $\begin{array}{l}20.22 / \\
20.22\end{array}$ & $\begin{array}{c}20.35 / \\
20.2\end{array}$ & $\begin{array}{l}19.98 / \\
19.92\end{array}$ \\
\hline
\end{tabular}


Final version appeared in JMMM Vol. 503, 1 June 2020, paper\#166636

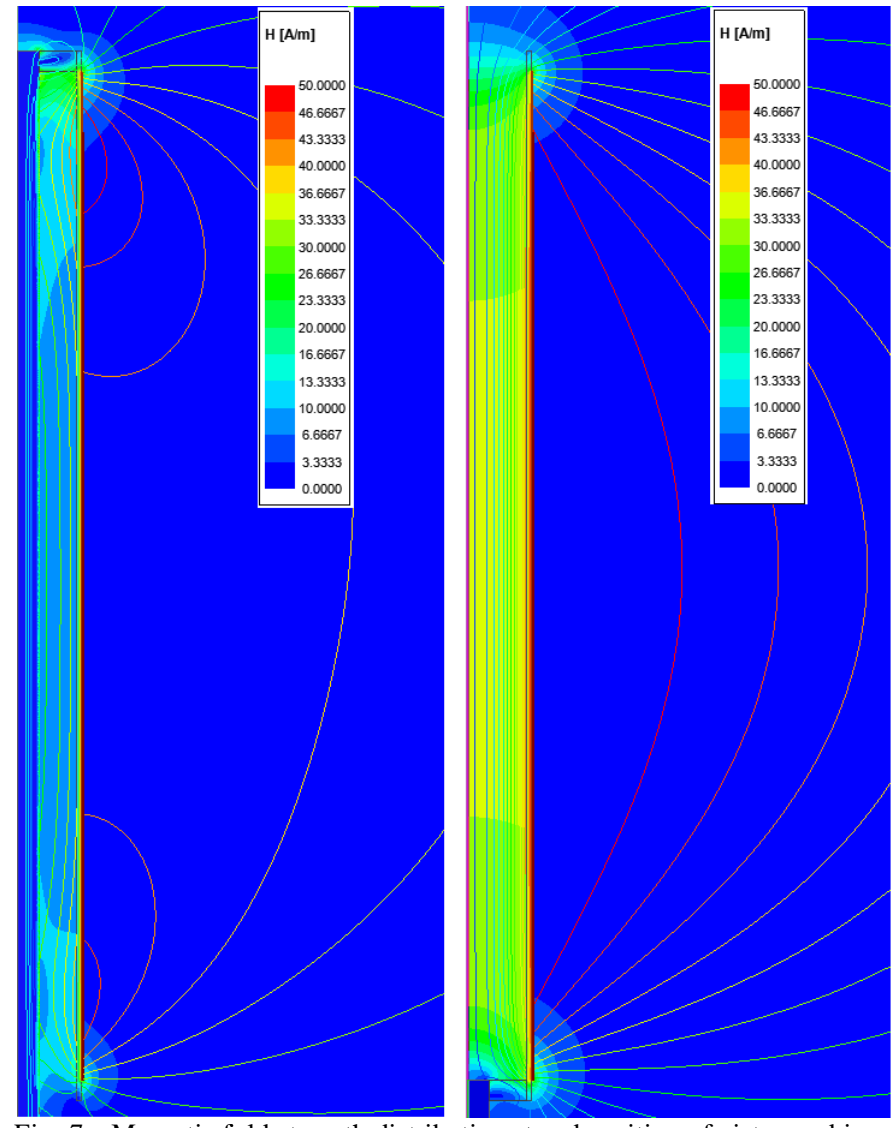

Fig. 7. Magnetic field strength distribution at end position of piston and iron rod (left) and starting position of piston and iron rod (right) at $100 \mathrm{~Hz}-\mathrm{FEM}$

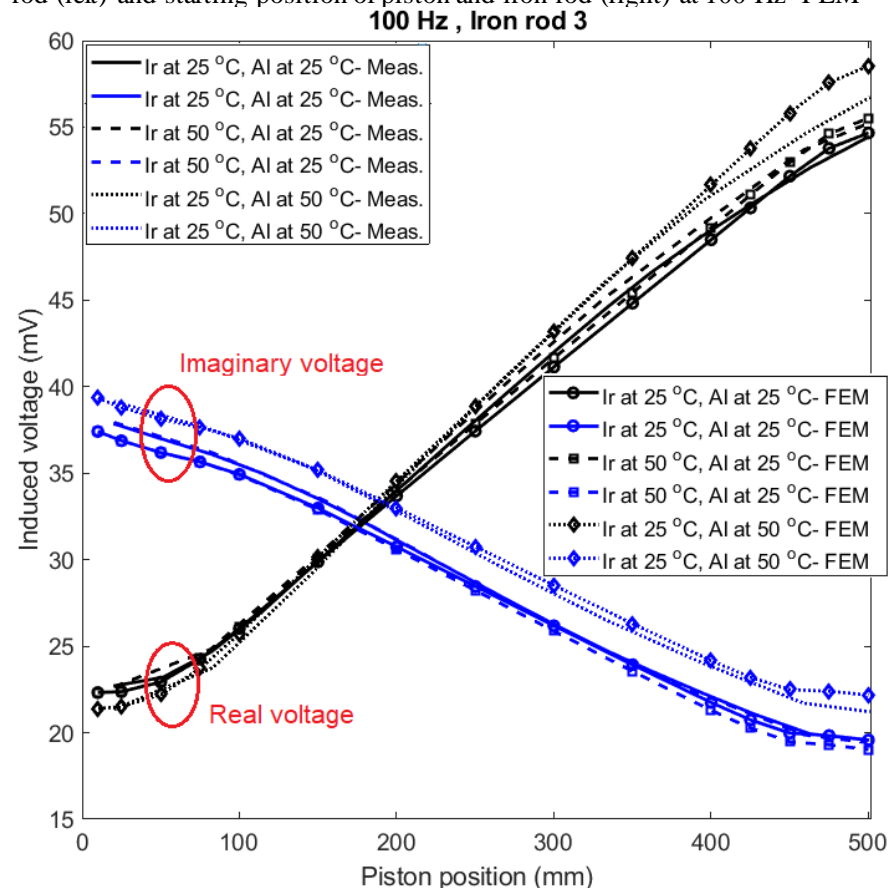

Fig. 8. Induced voltage of pick up coil versus iron rod and piston position at different temperatures of iron rod (Ir) and aluminum cylinder (Al)

Temperature rise in the aluminum cylinder has the main impact on the induced voltage of pick up coil in comparison with temperature rise in the iron rod as shown in Fig. 8. The resulting total position temperature error is $2 \mathrm{~mm} / \mathrm{K}$ for $\mathrm{Im}$ part, while for Re part the temperature dependence is more complex and cannot be described by simple coefficient.
FEM analyses show the same tendency as measurements. FEM analys is also shows that changing of relative permeability and conductivity of the iron rod has equal influence on the induced voltage (Table V).

$$
\text { Table V }
$$

Induced voltages $(\mathrm{mV})$ comparison at different iron rod 3

\begin{tabular}{|c|c|c|c|c|c|c|}
\hline \multirow[t]{2}{*}{$\begin{array}{c}\text { Piston } \\
\text { position }\end{array}$} & \multicolumn{2}{|c|}{$\begin{array}{c}\mu_{\mathrm{r}}=90.66 \\
\sigma=4.48 \mathrm{MS} / \mathrm{m} \\
25^{\circ} \mathrm{C}\end{array}$} & \multicolumn{2}{|c|}{$\begin{array}{c}\mu_{\mathrm{r}}=95.36 \\
\sigma=4.0 \mathrm{MS} / \mathrm{m} \\
50{ }^{\circ} \mathrm{C}\end{array}$} & \multicolumn{2}{|c|}{$\begin{array}{c}\mu_{\mathrm{r}}=90.66 \\
\sigma=4.0 \mathrm{MS} / \mathrm{m} \\
50{ }^{\circ} \mathrm{C}\end{array}$} \\
\hline & $\operatorname{Re}$ & $\mathrm{Im}$ & $\mathrm{Re}$ & $\mathrm{Im}$ & $\mathrm{Re}$ & $\mathrm{Im}$ \\
\hline \multirow{2}{*}{$250 \mathrm{~mm}$} & 37.43 & 28.46 & 37.85 & 28.23 & 37.72 & 28.32 \\
\hline & $100 \%$ & $100 \%$ & $101 \%$ & $99 \%$ & $101 \%$ & $100 \%$ \\
\hline \multirow{2}{*}{$450 \mathrm{~mm}$} & 52.17 & 19.98 & 52.96 & 19.47 & 52.71 & 19.67 \\
\hline & $100 \%$ & $100 \%$ & $102 \%$ & $98 \%$ & $101 \%$ & $99 \%$ \\
\hline
\end{tabular}

\section{CONCLUSION}

Thermal stability of transformer position sensor for a pneumatic sensor has been presented. Temperature of the aluminum cylinder has highest impact on the induced voltage; both real and imaginary components change considerably.

Using different solid iron rods with different relative magnetic permeabilities and conductivities has negligible effect on the measured induced voltage of the pick up coil especially at $200 \mathrm{~Hz}$. Excitation frequency $200 \mathrm{~Hz}$ is also more suitable for position sensing in dynamic conditions.

The effects of temperature on the induced voltage of pick up coil could be corrected using a compensating ring coil in the beginning of pneumatic cylinder as it would not be dependent on iron rod position. Another possibility is to measure the cylinder temperature and make compensation by calculations. Imaginary part of the induced voltage is more suitable for the temperature compensation, as the error is constant with position and the temperature position error can be expres sed by single coefficient.

\section{REFERENCES}

[1] P. Ripka, "Improved fluxgate for compasses and position sensors," Journal of Magnetism and Magnetic Materials, 83, pp. 543-544, 1990

[2] E. Hristoforou and H. Chiriac, "Position measuring system for applications in field sports," Journal of Magnetism and Magnetic Materials, 249, pp. 407-410, 2002

[3] J.J. Beato-Lopez, I. Royo-Silvestre and C. Gomez-Polo, "Micrometric non-contact position magnetoimpedance sensor," Journal of Magnetism and Magnetic Materials, 465, pp. 489-494, 2018

[4] H. Sumali, E.P. Bystrom and G.W. Krutz, "A displacement sensor for nonmetallic hydraulic cylinders," IEEE Sensors Journal, 2003, vol. 3 , no. 6, pp. $818-826$

[5] P. Ripka, A. Chirtsov, and M. Mirzaei, "Inductance position sensor for pneumatic cylinder", AIP Advances, 8, 2018, 048001

[6] M. Mirzaei, P. Ripka, A. Chirtsov, and J. Vyhnanek, "Temperature influence on position transducer for pneumatic cylinder", IEEE Sensors Conference 2018, India paper \#1638

[7] P. Ripka, M. Mirzaei, A. Chirtsov, and J. Vyhnanek, "Transformer position sensor for a pneumatic cylinder", Sensors and Actuators A: Physical, 294, pp. 91-101, 2019

[8] M. Mirzaei, P. Ripka, A. Chirtsov, and J. Vyhnanek, "Eddy current linear speed sensor," IEEE Trans. Mag., vol. 55 , no. 1, pp. 1-4, 2018

[9] R. L. Sanford, "Temperature coefficient of magnetic permeability within the working range," Dept. of Commerce, Bureau of Standards, 1915

[10] M. Sridhar, Y. Aparna, J. Kishore Babu, and G. Patrick, "Studies on conversion of thermal energy into electrical energy using ferromagnetic mild steel, cobalt and nickel as core materials: comparative study," AIP Conference Proceedings 2104, 030022 (2019) 